\title{
Construct Scheme to Enterprise Staff Performance Management System
}

\author{
Zhang Jian \\ Human Resource Operation Department \\ China-Power Information Technology Limited \\ Company \\ Beijing,China \\ zhangjian9@sgepri.sgcc.com.cn
}

\author{
He Jianbo \\ Human Resource Operation Department \\ China-Power Information Technology Limited \\ Company \\ Beijing,China \\ hejianbo@sgepri.sgcc.com.cn
}

\begin{abstract}
In terms of adapting the revolution of "Three Centralization Five Huge" reform, constructing scientific and standard enterprise staff performance management system, improving stimulation constraint mechanism, enhancing staff working enthusiasm, as well as ensuring and promoting "One Strong Three Brilliant” modern company construction, State Grid company has built an unified standard information system, which is operation horizontal integrated and data vertical connected. Effectively, the system provides information support for staff performance management implementation. In this paper, we introduce the overall architecture, deployment scheme and application integration scheme for the Enterprise Staff Performance Management Information System.
\end{abstract}

Keywords- SGERP-HR; Performance Management Systerm; Enterprise Staff Performance Management Information System ; Application Integration

\section{FOREWORD}

Staff performance management, as emphases of human resource management in examination, assessing and check on work attendance for State Grid Company, is required to deepen management constantly, develop innovation, so as to construct effective performance management model, accommodating the distinctive operating way of company. We should focus on "Three Strong Five Huge" holistic work, and make relative adjustment to adapt the organization under "Five Huge" business pattern, as well as the change of management model and work flow. Moreover, we should enhance the integration and support for the new "Five Huge" business operating model in order to serve the strategy target of realizing "One Strong Three Brilliant" modern company.

According to staff performance management requirement provided by State Grid Company, we design the core business architecture and component, referring to the best practice from both here and abroad. The enterprise staff performance management system inherits and improves the "SG-ERP" system. It deepens application and improves innovation. It builds a highly integrative information platform which integrating corresponding business application, with effective security system. The unified information system can strength the development of human resource management, support the construction of "Strong Smart-grid”, “Three Centralization Five Huge” and the strategy target of “One Strong Three Brilliant” modern company construction.

The design and development of enterprise staff performance management system includes platform centralization, application integration, general configuration component development, security assurance. The main character of this system is that it has better flexibility, deeper integration, higher intelligence, stronger security, better interaction and visualization. As an important component of enterprise management and SGERP-HR architecture, the enterprise staff performance management system is facing a new development chance, which includes business integration, deepen application and system improvement. The enterprise staff performance management platform comprises organization management system, performance index system, performance evaluation system, evaluation result application system and security system. Moreover, it is highly integrated with SGERP-HR, as well as all aspects of human resource, and will become the key work of SGCC human resource information construction.

\section{TOTAL FRAMEWORK}

\section{A. Operation framework}

Enterprise staff performance management is mainly to achieve performance appraisal for the person in charge of enterprise (city company and below), administrative authority (provincial company and below) and frontline staff (city company and below).

Performance management process in this paper cover the whole performance process as following: performance objective management, performance strategy and planning, performance implementation, procedure control and performance result application. Figure 1 shows the operation framework as follow. 


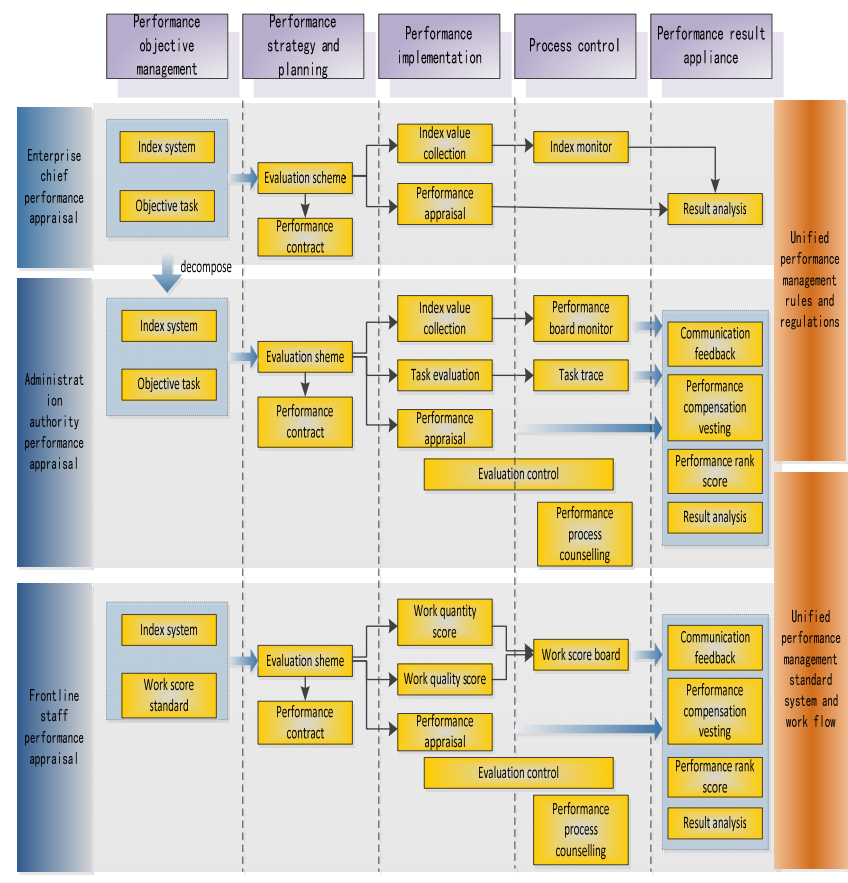

Figure 1. Operation framework of Enterprise Staff Performance Management

Technology framework of the enterprise staff performance management system, for all level companies, is the same, including three layers: interface layer, function layer and data layer. As figure 2 shows, it realizes the integration of performance management and human resource control from the aspect of interface, function and data layer.

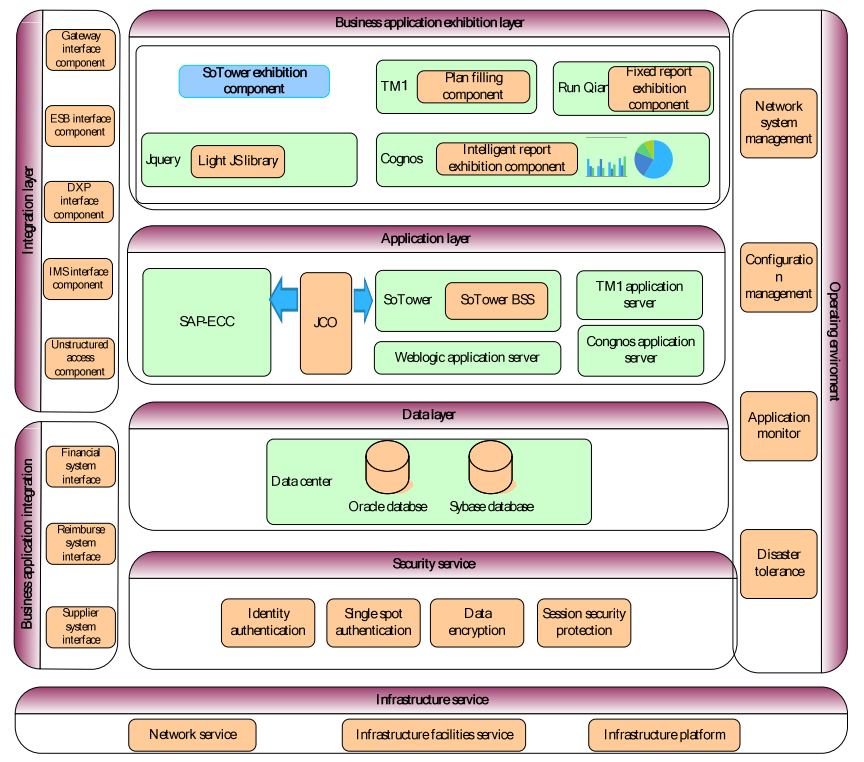

Figuer 2. Technique framework of Enterprise Staff Performance Management System
Exhibition layer: We realize the united entrance and single login spot to control user access, thus, all business modules of performance management are integrated with united user interface.

Function layer: This layer includes human resource model, analysis function and expert system.

Data layer: The function data of enterprise staff performance management system stores in ERP, while expert systems stores data in their databases, and synchronize the business data to the native data center.

\section{B. Data framework}

According to the design concept and principle of SGERP data architecture, we organize and plan data, in an unified manner, from the perspective of global business of staff performance management, so as to improve the efficiency of data storage and sharing among systems. From the point of enterprise data asset management, we formulate the whole data life circle, which includes collection, storage and flow of data, as well as strategy, model and process of access control.

Moreover, system divided into six subject fields in accordance with the business characteristic, including index system, task management, evaluation strategy, evaluation planning, evaluation implementation and results management, as figure 3 shows.

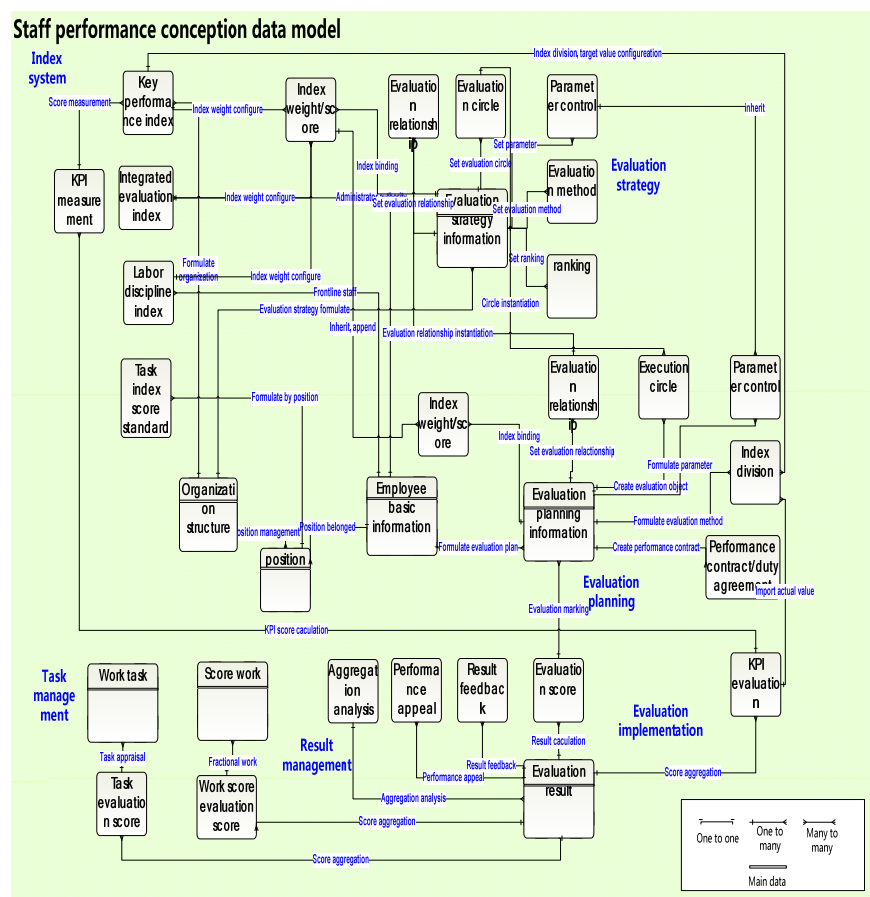

Figure 3. Data framework of Enterprise Staff Performance Management System 


\section{Application framework}

Enterprise staff performance management business application includes seven components: index system management, evaluation strategy management, evaluation planning management, evaluation implementation management, task management, performance board management and performance results management. Effectively, all of these applications have formed a closed loop management, which consist of performance objective, responsibilities, evaluation, rewards and punishment and supervision. The enterprise staff performance management application architecture is presented as follow.

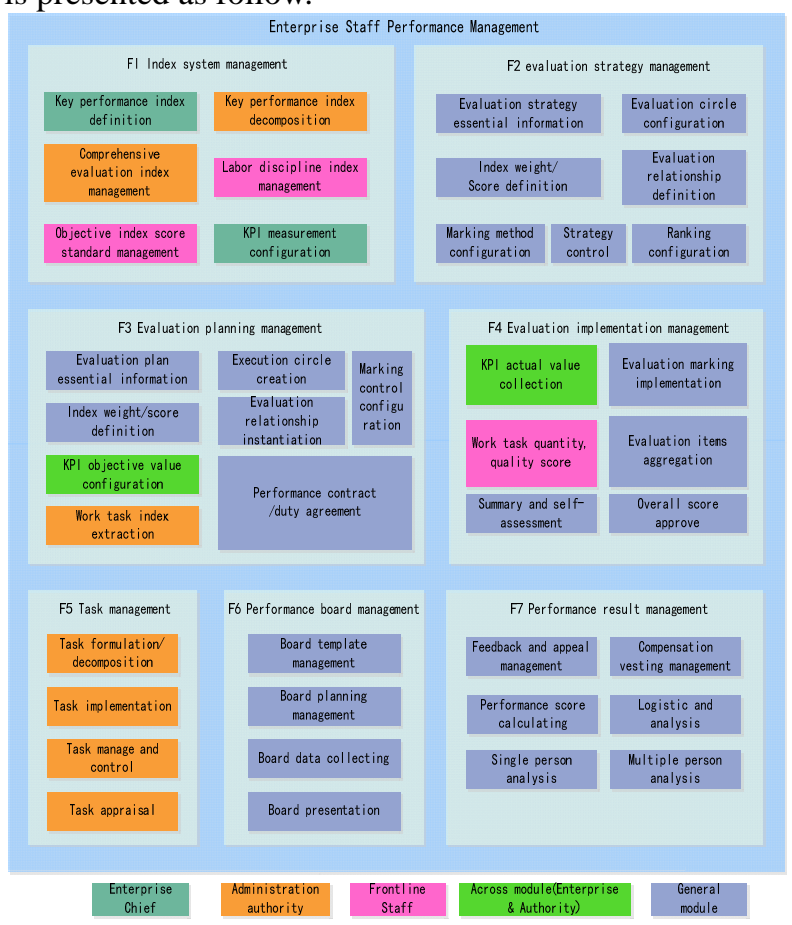

Figure 4. Application framework of Enterprise Staff Performance Management System

\section{Security framework}

We design the security architecture for the enterprise staff performance management system, as figure 5 shows, consisting physics security, network security, system security, application security and data security.

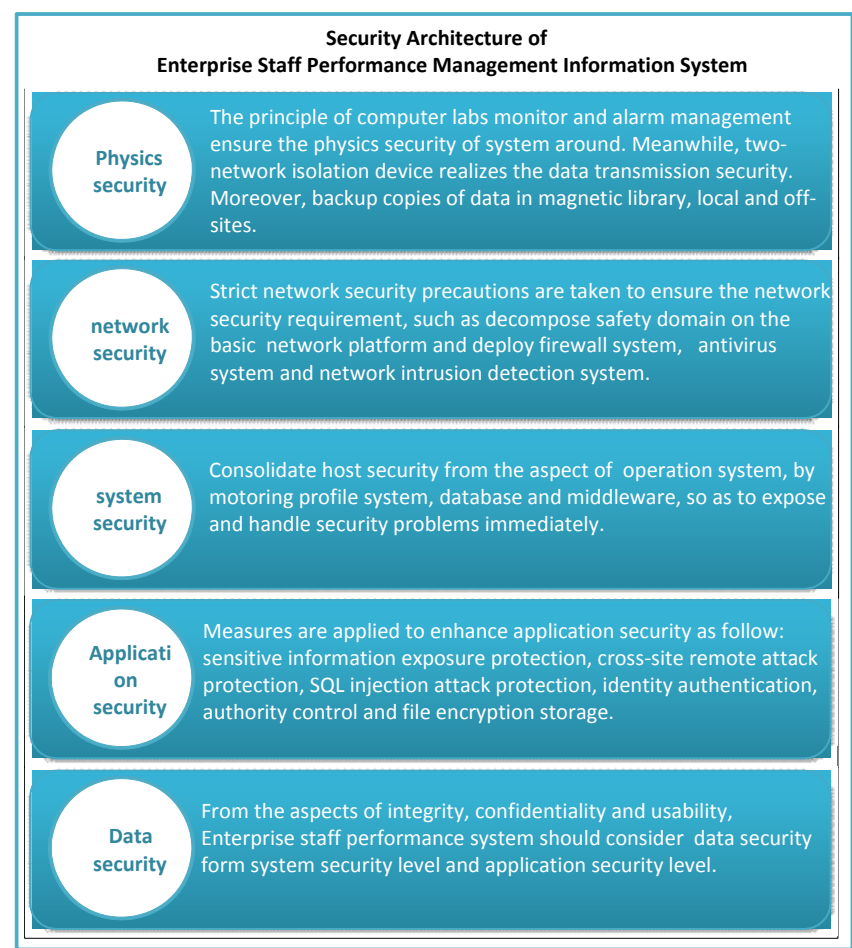

Figure 5. Safe framework of Enterprise Staff Performance Management System

\section{DEPLOYMENT SCHEME}

Enterprise staff performance management system is deployed by an approach with highly available cluster in which the database and application server are deployed via an approach of dual-node. It uses database RAC, Weblogic cluster and F5 loader balance device to provide highavailability service.

The application server deployment for provincial company of Enterprise staff performance management system shows as figure 6 .

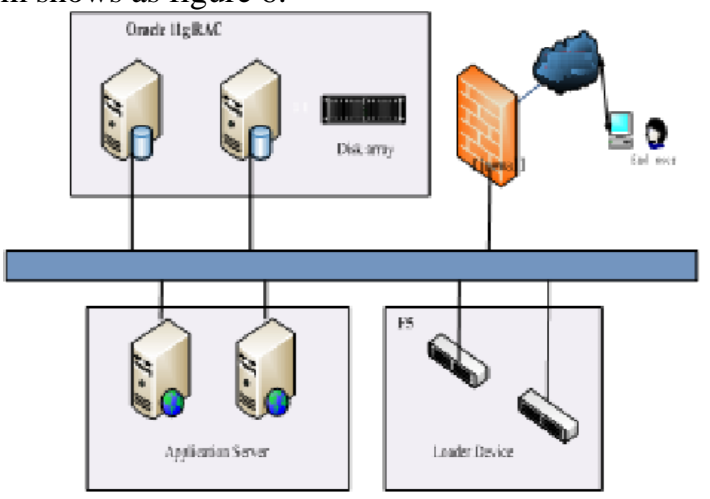

Figure 6. Deployment framework of provincial company

\section{APPLICATION INTEGRATION SCHEME}

\section{A. Directory integration scheme}

User is required to fill in the form of enterprise staff performance management system through directory after logon portal. The directory passes username and password 
to SGERP-HR management system after authentication of status authentication server finished. The rule is: the user finishes authentication by status authentication server at the first time, the directory will deliver accounts information to the application system requested by user through the following principles:

1) If user's account in application system consistent with that in authentication directory, user properties in directory, such as username and password, will be filled in application system login form automatically, and then be submitted to application server.

2) Otherwise, there are two available methods:

a) The first time user login, information like username and password are required, which will be preserved into authentication system in encryption way. Later, when the user uses the same URL to access this application system, the authentication system will automatically fill in the login form and submit, using user's information preserved.

b) Also, we can map user account information in the application system to the directory as extended property. When user logins, user's extended property in directory will be access and submitted to the application system.

\section{B. Portal integration scheme}

The enterprise staff performance management system sends pending proceedings to the pending proceeding disposal platform via web service, after then, enterprise portal can access these pending proceedings via data access interface and present them comprehensively.

\section{Human resource system integration scheme}

The main purpose of integration between enterprise staff management system and human resource system is to deliver staff performance results and compensation vesting proposals to compensation management system. The enterprise staff management system proposes compensation vesting proposal according to staff performance evaluation result, and then deliver it to compensation module in human resource system, in which we will realize the final compensation vesting function.

\section{TAG}

Guided by this scheme, we have started building the enterprise staff performance management system since Dec 2012. So far, we have finished "user requirement specification”, "software requirement specification”, ” outline design specification”, “database design specification" and "detailed design specification". Meanwhile, the basic platform framework has been developed, as well as certain module, such as index system management, evaluation strategy management, evaluation planning management, task management and so on. Also other modules are on developing, such as evaluation implementation management. We plan to complete the development of all modules by mid-December 2013, to complete unit testing, integration testing, third-partner testing and security testing before January 2014, finally to carry out experimental running in Ningxia company at February 2014.

\section{REFERENCES}

[1] State Grid company "12th five-year" informative development layout.

[2] State Grid company "12th five-year" human resource informative development layout.

[3] State Grid company staff performance management tentative measures (State Grid Human Resource[2012] 836).

[4] Zhang Jian, Wang Ben, "Construct Scheme to SG-ERP Human Resource Management Information System First-period of State Grid Compan.”,CSSS 2012, Aug. $11^{\text {th }}$ to $13^{\text {th }}, 2012$ in Nanjing, China. pp.893-899.

[5] Zhang Jian, Wang Ben, He Jia, "Construct Scheme to SG-ERP Human Resource Management Information System Second-period of State Grid Company”. ICM 2013, June 3 $3^{\text {th }}, 2013$.

[6] State Grid company chief manager annual performance management layout

[7] State Grid company chief manager annual performance management layout for industrialization company

[8] State Grid company chief manager annual performance management layout for financial company

[9] State Grid company staff performance management assesment evluation layout

[10] State Grid company front-line worker annual performance management layout 